\title{
Single- and repeated-dose toxicities of aloe fermentation products in rats
}

\author{
Ju-Hyun Cho ${ }^{1 *}$, Hyun-Kyoung Kim ${ }^{1}$, Soon-Ok Baik', Soo-Young Choi ${ }^{2}$, Jae-Young Lee ${ }^{1}$ \\ ${ }^{1}$ Hurum Central Research Institute, Ochang, Korea \\ ${ }^{2}$ College of Biology, Chungbuk National University, Cheongju, Korea
}

\begin{abstract}
In this study, aloe fermentation products were derived from mycelia from 3 mushrooms: Ganoderma lucidum (AG), Hericium erinaceum (AH), and Phellinus linteus (AP). Levels of aloin A and B increased with fermentation time. The highest levels were measured on the fifth day of fermentation. $\beta$-Glucan levels decreased with fermentation time. The safety of aloe fermentation products were examined in male and female Sprague-Dawley rats. Rats were orally administered the three aloe fermentation products at dose levels of 1, 2 or $5 \mathrm{~g} / \mathrm{kg}$ for single-dose toxicity test and $0.5,1$, or $2 \mathrm{~g} / \mathrm{kg}$ for repeated-dose toxicity test. There were no significant differences in body weight gain between vehicle control and AG-, AH- or AP-treated rats. Also, significant changes in daily feed intake and water consumption were not observed. In hematological analysis, none of the parameters were affected by aloe fermentation products with mushroom mycelia. This suggests that there are no negative effects on homeostasis and immunity. In blood biochemistry analysis, none of the markers were affected by feeding rats with AG, AH or AP. Similarly, there were no significant effects on markers for liver, kidney, skeletal and heart muscle functions. No remarkable lesions were observed in these organs at histopathology. Since there were no adverse effects of AG, AH and AP in single- or repeated-dose toxicity tests, even at higher doses than normal, we conclude that the aloe fermentation products with mushroom mycelia possess long-term safety and could be candidates as multifunctional nutrients for the improvement of intestinal function and immunity.
\end{abstract}

Key words: Aloe fermentation, aloin, $\beta$-glucan, Ganoderma lucidum, Phellinus linteus, Hericium erinaceum, single-dose toxicity test, repeated-dose toxicity, Sprague-Dawley rat

Received 27 July 2011; Revised version received 14 September 2011; Accepted 14 September 2011

Aloe is a perennial plant taxonomically grouped under the phylum Aloe, order Lily and family Liiaceae. It has been used as an herbal medicine for 3,000 years [1]. Currently, the leaves of Aloe vera, Aloe arborescence, and Aloe saponaria are used as health promoting foods. Aloe gel is obtained from bigger leaves of Aloe vera and prepared as a health functional food by removing the non-edible parts and peeling off the epicarp. The main ingredients of Aloe vera gel are a polysaccharide polymer, alomichin, aloin, aloetic acid and aloe ulcin, which have antitumor effects, strengthen immunity, enhance cell reproduction and improve stomach function [2-6]. Despite these various effects of Aloe vera gel, its use is limited to its being a notification functional food for 'improving intestinal function and immunity' and 'skin care' by the Korea Food and Drug Administration (KFDA). Although several studies on aloe have indicated its usefulness in improving gastrointestinal function [2-6], those studies are not recognized by KFDA. Aloe gel as a heath functional food notification material is consumed directly in its natural state. The biggest problem is the conventional image of aloe, because it can be consumed directly from raw material. Stocking is also a major problem as aloe gel is a jelly. However, there are many studies that described product differentiation for aloe usage $[3,5]$.

*Corresponding author: Ju-Hyun Cho, Hurum Central Research Institute Co., Ltd, 685-1 Yangcheong-ri, Ochang-eup, Cheongwongun, Chungbuk 363-883, Korea

Tel: +82-43-217-1077; Fax: +82-43-217-1088; E-mail: dusvnd608@hurum.co.kr

This is an Open Access article distributed under the terms of the Creative Commons Attribution Non-Commercial License (http://creativecommons.org/licenses/ by-nc/3.0) which permits unrestricted non-commercial use, distribution, and reproduction in any medium, provided the original work is properly cited. 
Mushrooms contain a greater variety of nutrition (such as carbohydrates, protein, vitamins and minerals) than vegetables. They have been used as food and medicine since ancient times and are regarded by some people as a favorite food on account of their unique taste and flavor [7]. Recently, there have been many scientific studies on the ability of mushrooms to improve immunity, lower cholesterol, normalize blood-sugar levels, and to have anti-cancer, anti-microbial and antihypertensive effects [8-13]. In particular, a liquid culture method using the mushroom mycelium, which enables the production of large amounts of bioactive compounds in a short period of time and at lower cost, has been studied for possible utilization on an industrial scale. Ganoderma lucidum, which was used in our study, is in the Polyporaceae of basidiomycetes family and is used a diuretic, a tonic, and for improving immunity against anti-cancer [11,14-16]. It was proven safe in an animal experiment of acute and subacute toxicity using extracts of the whole plant. The second mushroom used in this study, Hericium erinaceum, has also been used as food and medicine for a long time. It is effective in chronic gastritis, cancer (especially gastric cancer), and in physical weakness. In a recent study, material for a potential Alzheimer cure was extracted into hot water from Hericium erinaceum. The hot-water extract also had anti-tumor effects - it restricted cancer cell proliferation. Hericium erinaceum contains $\beta$-glucan, which enhances immunity and prevents arteriosclerosis [17-19]. The third mushroom used in this study is Phellinus linteus. It is effective in improving immunity during chemotheraphy after cancer surgery, especially for gastrointestinal malignancies such as stomach, esophagus, duodenum, colon, rectum and liver cancers. It also has effects on metrorrhagia, leukorrhea, irregular menstruation, enterohemorrhage. It improves stomach function and can be used for detoxification [16].

There have been no reports on the nutritional and toxic effects of products from the above mushrooms that have been fermented in aloe. In this study, we examined a new and improved functional material of aloe fermented using mushroom strains. For safety evaluation and standardization of the fermentation products, single-dose and repeated-dose toxicity tests were performed with the standard being toxicity tests of KFDA (Regulation 1999-61).

\section{Materials and Methods}

\section{Experimental animals}

Male and female healthy Sprague-Dawley rats (150-200 g), from Daehan Bio-Link Inc. (Eumsung, Korea), were used after 1-week acclimation to the laboratory environment. The experiment was performed in the animal laboratory under conditions of $23 \pm 3^{\circ} \mathrm{C}$, a relative humidity of $55 \pm 15 \%$, 12 h of lighting (08:00-20:00) at 150-300 Lux of brightness. During the experimental period, the rats were kept in stainless mesh cages $(220 \mathrm{~W} \times 410 \mathrm{~L} \times 200 \mathrm{H} \mathrm{mm})$. Two to three rats in each cage were kept for the adjustment, during the test product administration and observation periods. The animal experiments were performed with permission from The Ethics Committee of Animal Experiments at Chungbuk National University, Korea.

\section{Materials}

Ganoderma lucidum (KCTC 6729) and Phellinus linteus (KCTC 6719) were used as standard strains. They were acquired from the Gene Bank of The Korea Biological Resource Center. Hericium erinaceum was obtained from the Food-Engineering Department of Chungju National University (Jeungpyeong, Korea). Each strain was cultivated in potato dextrose agar (PDA, Difco, Detroit, USA) by 15 days of subculturing [18,20]. Aloe (Aloe vera) was purchased from JejuSamda Aloe (Jeju, Korea) in 2009 and 2010. Aloin A and aloin B were from ChromaDex (Irvine, USA) and were used as standards for aloe products. Mushroom and yeast $\beta$-glucan kits were from Megazyme (Wicklow, Ireland) and were used for $\beta$-glucan analysis. Levels of aloin A, aloin B and $\beta$-glucan were standardized by analyzing the aloe fermentation products for a general toxicity evaluation.

\section{Cultivation conditions for strains and manufacturing of liquid spawn}

Manufactured strains of Ganoderma lucidum and Phellinus linteus (in all liquid cultures) were incubated in PDA medium for 7 days at $28^{\circ} \mathrm{C}$. Strain discs were created by cutting with a cork borer (8 $\mathrm{mm}$ in diameter). Five to six discs were placed in an Erlenmeyer flask which contained $100 \mathrm{~mL}$ of potato dextrose broth (PDB, Difco) medium, and then were shaken and cultured (SI-400R; Jeiotech, Daejeon, Korea) for 6 days. The culture was then homogenized using a grinder. Nine milliliters of this was subsequently placed in an Erlenmeyer flask in which $100 \mathrm{~mL}$ of PDB was left for 5 days. These were used as the main spawn. Hericium erinaceum was processed by the same method as above but the temperature was kept at $24^{\circ} \mathrm{C}[18,20]$.

\section{Cultivation of mushroom mycelium in aloe as a natural medium \\ To obtain the viscosity of aloe gel, fresh leaves were washed, peeled and ground. The gel was placed in a fermenter and sterilized for $20 \mathrm{~min}$ at $120^{\circ} \mathrm{C}$. The temperature of the}


fermenter was rapidly cooled to $25^{\circ} \mathrm{C}$ and the resulting aloe gel was used as a natural medium. Aloe fermentation products were obtained by cultivating $9 \%$ of the liquid spawn in the gel at an optimum temperature. These aloe fermentation products were extracted at $85^{\circ} \mathrm{C}$ for $6 \mathrm{~h}$, filtered using filter paper (Advantec 5A; Advantec, Tokyo, Japan), and then evaporated and freeze-dried (Ilshinbiobase, Dongducheon, Korea). The freeze dried aloe fermentation products were used as the experimental samples.

\section{Aloin A and aloin B levels}

The concentrations of aloin $A$ and aloin $B$ were determined using a high performance liquid chromatography system (Waters 2695; Waters, Milford, USA)-photodiode array detector (PDA, Waters 996; Waters) with a fixed YMC-PACK PRO $\mathrm{C}_{18}(5 \mu \mathrm{m} 4.6 \times 150 \mathrm{~mm}$ AS12S05-1546WT) [21,22].

\section{$\beta$-Glucan analysis}

One hundred $\mathrm{mg}$ of aloe fermentation product was placed in a $50 \mathrm{~mL}$ glass test tube, and $1.5 \mathrm{~mL}$ of $37 \%$ hydrochloride was added. A reaction was made to occur every $15 \mathrm{~min}$ for $45 \mathrm{~min}$ in a $30^{\circ} \mathrm{C}$ water bath. Ten $\mathrm{mL}$ of distilled water was added and then reacted in boiling water for $5 \mathrm{~min}$ and the contents of the tube were stirred in a $100^{\circ} \mathrm{C}$ water bath for $2 \mathrm{~h}$. They were allowed to cool and then $2 \mathrm{~N} \mathrm{KOH}$ $(10 \mathrm{~mL})$ was added. The contents were centrifuged at 3,000xg for $10 \mathrm{~min}$ and the supernatant was collected. Exo-1,3- $\beta$ glucosidase $(0.1 \mathrm{~mL})$ was added to an equal volume of supernatant. A reaction was made to occur at $40^{\circ} \mathrm{C}$ for 60 min and total glucan was determined. Aloe fermentation product (100 mg) was placed in a $50 \mathrm{~mL}$ glass test tube and $2 \mathrm{M} \mathrm{KOH}(2 \mathrm{~mL})$ was added and placed in an ice water bath for 20 min. Next, 1.2 M sodium acetate buffer $(\mathrm{pH} 3.8$, $8 \mathrm{~mL})$ and amyloglucosidase plus invertase $(0.2 \mathrm{~mL})$ were mixed and placed in a $40^{\circ} \mathrm{C}$ water bath for $30 \mathrm{~min}$. This was centrifuged at $3,000 \times g$ for $10 \mathrm{~min}$. Then $200 \mathrm{mM}$ sodium acetate buffer ( $\mathrm{pH}$ 5.0) was added to the supernatant and $\alpha$-glucan levelswere determined. Glucose oxidase/peroxidase/ 4-amino-anipyrine (GOPOD) reagents $(3 \mathrm{~mL})$ were placed in each of the total glucan and the $\alpha$-glucan analyzing flasks, and the flasks were placed in a $40^{\circ} \mathrm{C}$ water bath for 20 min. Absorbance was observed at $510 \mathrm{~nm}$ and the $\beta$-glucan content (\%) in the sample was calculated $[14,23]$.

\section{Manufacturing and applying aloe fermentation products}

Three aloe fermentation products (Ganoderma lucidumaloe fermentation product (AG), Hericium erinaceum-aloe fermentation product $(\mathrm{AH})$ and Phellinus linteus-aloe fermentation product (AP) were used for both single-dose toxicity and repeated-dose toxicity tests. The toxicity tests were performed for the validity of food safety. Three different dosages (1, 2 and $5 \mathrm{~g} / \mathrm{kg}$ ) and $(0.5,1$ and $2 \mathrm{~g} / \mathrm{kg}$ ) of each experimental material ( $\mathrm{AG}, \mathrm{AH}$ and $\mathrm{AP}$ ) were, respectively, used for single-dose and repeated-dose toxicity tests. They were orally administered.

\section{Toxicity tests}

For single-dose toxicity test, a total of 80 rats were assigned to vehicle, AG, AH and AP groups, with each group accounting for 3 dose levels of 4 mice each with a total of 10 groups. After 24-h fasting, the test materials, dissolved in purified water, were administered orally using a syringe with a Sonde needle. According to the guidelines of KFDA and Health and Welfare Department of Japan, the upper-limit dosage was set at $5 \mathrm{~g} / \mathrm{kg}$ (3-dose levels of 1, 2 and $5 \mathrm{~g} / \mathrm{kg}$ ). Feed were provided after $4 \mathrm{~h}$ of test material administration, and toxicity was evaluated for a 2-week observation period [24-26].

For repeated-dose toxicity tests, the general procedure followed was the same as the above indicated single-dose toxicity test except that the 3-dose levels used in repeateddose toxicity tests were $0.5,1$ or $2 \mathrm{~g} / \mathrm{kg}$ without fasting. The animals were administered for 28 days, and 10 rats were in each group (a total of 100 rats).

\section{Observation of clinical signs}

Based on the Functional Observational Battery (FOB) tests, such as function of the automatic nervous system, home cage, open field behaviors, reaction to stimulation, alertness, vigilance, posture, walking and mortality examinations were done every day during the experimental period. In addition to general symptoms, body weight as well as feed and water intakes were observed and recorded every week. At the end of the trial, rats were anesthetized with ether, the abdomen was opened, and the animals were killed by bleeding. Organs were examined with the naked eyes.

\section{Hematological analysis}

Blood was collected from the abdominal artery into an EDTA tube (BD vacutainer, BD, Franklin Lakes, USA). Hematocrit, red blood cells (RBC) and RBC indices, platelets, white blood cells (WBC) and differential counts were analyzed using a hematology analyzer (Siemens Medical ADVIA 2120, Bayer, Leverkusen, Germany).

\section{Blood biochemical analysis}

Blood was collected from the abdominal artery into a test tube. After standing for $30 \mathrm{~min}$, the blood was centrifuged 
for $10 \mathrm{~min}$ at $12,000 \mathrm{rpm}$ and the serum was collected. Hepatic toxicity indices (alanine transaminase, ALT; aspartate transaminase, AST; alkaline phosphatase, ALP; total proteins, TP; albumin; total bilirubin, TB; glucose), lipid metabolism indices (total cholesterol, TC; triglycerides, TG), and renal toxicity indices (blood urea nitrogen, BUN; creatinine) were measured using a Clinical Analyzer (Hitachi 7080 Clinical Analyzer, Hitachi, Tokyo, Japan).

\section{Histopathological findings}

For histopathological findings, liver, lung, spleen, kidney, heart, testis, ovary, adrenal gland, thymus and brain were collected and fixed in $10 \%$ formalin for 3 days. Paraffinembedded tissue sections ( $4 \mu \mathrm{m}$ in thickness) were stained with hematoxylin-eosin, and examined with a light microscope.

\section{Statistics}

The data were analyzed by Kruskal-Wallis ANOVA and are presented as the mean $\pm \mathrm{SD}$.

\section{Results and Discussion}

The contents of aloin and $\beta-D-$ glucan in the aloe fermentation products

Since aloin A and B are well known as major active ingredients in aloe species, we determined the concentration of aloin $A$ and aloin $B$ in aloe fermentation products $A G$, $\mathrm{AH}$ and $\mathrm{AP}$. The contents of aloin $\mathrm{A}$ in control samples (aloe alone) or in fermented samples with $\mathrm{AG}, \mathrm{AH}$ and $\mathrm{AP}$, are indicated in Table 1. Aloe fermentation with mushroom mycelia increased the aloin A content in the fermentation products with the highest level observed in AP followed by $\mathrm{AH}$; AG had no effect. Similarly, aloin B proportions in all 3 mushroom mycelia-fermented products were significantly increased: $\mathrm{AP}>\mathrm{AH}>\mathrm{AG}$.

Since $\beta$-D-glucan is a multi-functional polysaccharide isolated from aloe species, we examined whether fermentation treatment affected polysaccharide composition. While the difference in proportion of $\beta$-D-glucan between un-treated control and Ganoderma lucidum-fermented aloe (AG) were not significant, $\mathrm{AH}$ and AP caused a significantly lowered $\beta$-D-glucan content than control (Table 1).

Toxic symptoms, clinical signs and mortality rates In the present study, general symptoms, clinical signs and mortality rates were examined at the given doses of the aloe fermentation products as indicated in the Materials and Methods section at $0,1,3$, and $7 \mathrm{~h}$ and then daily for 14
Table 1. Content of aloin $A$, aloin $B$ and $\beta$-glucan in aloe fermentation products

\begin{tabular}{|c|c|c|c|}
\hline Material & Aloin A (mg/kg) & Aloin B (mg/kg) & $\beta$-glucan (\%) \\
\hline AN & $32.3 \pm 1.64$ & $17.1 \pm 3.52$ & $11.1 \pm 0.65$ \\
\hline$A G$ & $32.1 \pm 1.61$ & $25.9 \pm 1.61$ & $11.2 \pm 0.92$ \\
\hline $\mathrm{AH}$ & $39.7 \pm 3.21$ & $29.9 \pm 2.82$ & $2.5 \pm 0.11$ \\
\hline AP & $44.0 \pm 1.89$ & $38.8 \pm 2.00$ & $4.9 \pm 0.35$ \\
\hline
\end{tabular}

AN: natural aloe, AG: aloe fermentation product fermented by Ganoderma lucidum, AH: aloe fermentation product fermented by Hericium erinaceum, AP: aloe fermentation product fermented by Phellinus linteus.

days after treatment. All the aloe fermentation products (AG, $\mathrm{AH}$ and $\mathrm{AP}$ ) did not cause any symptoms or abnormal clinical signs, and no deaths were observed during the study period (data not shown). According to the results from the singledose toxicity study, we set the dosage levels at 0.5, 1 and $2 \mathrm{~g} / \mathrm{kg}$ for repeated-dose toxicity test. In repeated-dose toxicity test, the results were similar: neither abnormal symptoms, nor deaths were observed (data not shown). The results indicate that $\mathrm{AG}, \mathrm{AH}$ and $\mathrm{AP}$ even at upper-limit doses do not induce any apparent clinical signs.

\section{Feed and water intakes and body weight gains}

In single-dose toxicity test, there were no significant differences in the body weight gain of male and female rats treated with aloe fermentation products (data not shown). In repeated-dose toxicity study, daily feed intakes were within 20-30 g and 10-15 g in all groups of male and female animals, respectively. Also, daily water intakes changed within 25-45 $\mathrm{mL}$ and $18-30 \mathrm{~mL}$ in male and female rats, respectively. There were no differences in the feed and water consumptions between control and aloe fermentation products (AG, $\mathrm{AH}$ and AP)-treated groups.

In addition, there were no differences in body weight gains between control and treatment groups, ranging from 96.4 to $123.3 \mathrm{mg} /$ day/rat regardless of the doses used (Figure 1), which may be in correlation with the feed and water intakes.

The above results for single-dose and repeated-dose toxicity tests suggest that the aloe fermentation products were not toxic to rats even at the highest (upper-limit) dose of $2 \mathrm{~g} / \mathrm{kg}$.

\section{Organ weights}

After 4 weeks of treatment, the weight of internal organs of rats was measured. Liver, kidneys, lung, heart, thymus, spleen, adrenal glands, and reproductive organs (testes and epididymides) of aloe fermentation products-treated male rats were not different from vehicle controls in all groups tested (Table 2). Similarly, liver, kidneys, lung, heart, thymus, spleen, adrenal glands, and reproductive organs (uterus and overies) 
Male

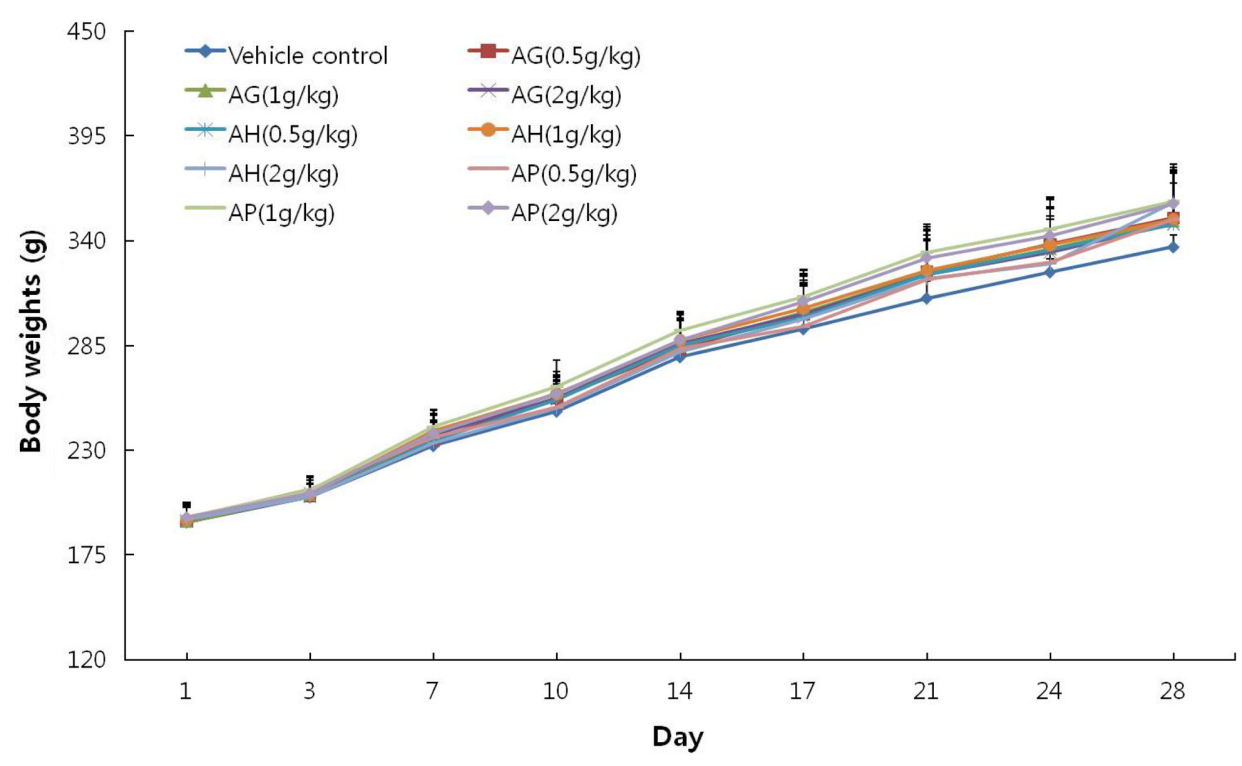

Female

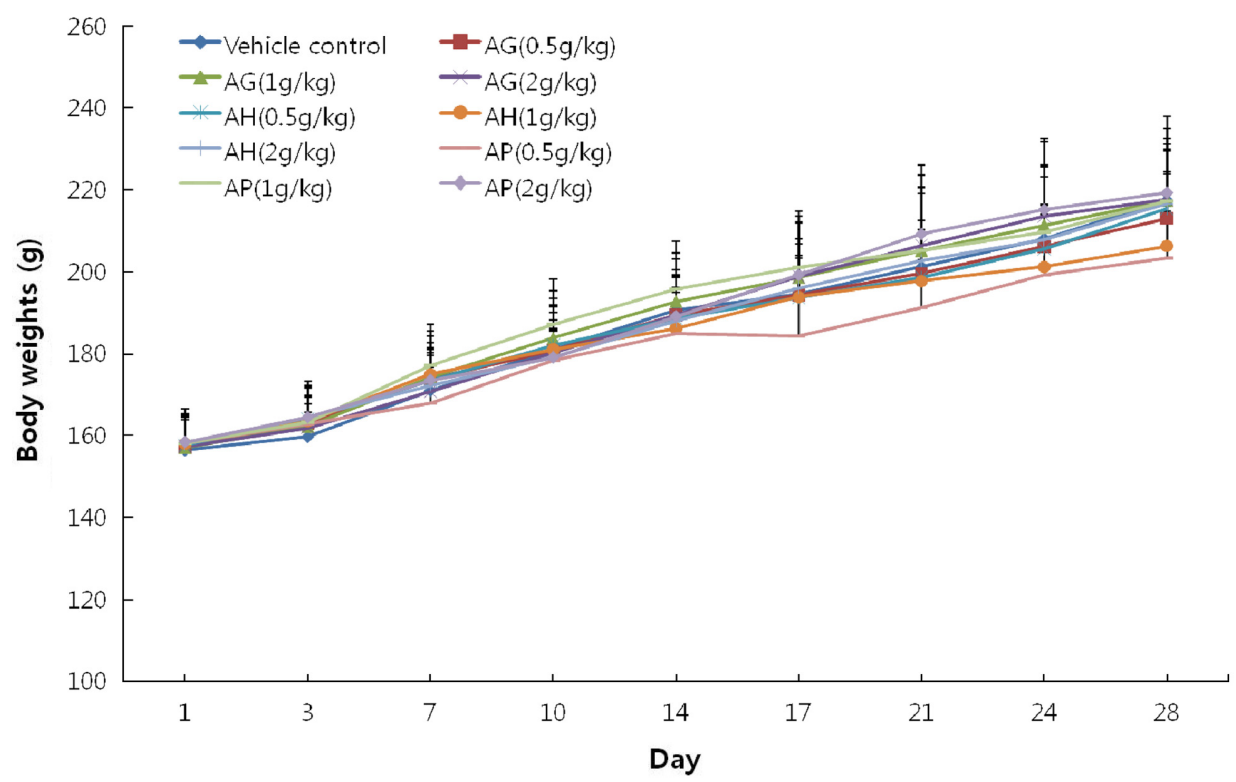

Figure 1. Changes in body weights of male and female rats fed aloe fermentation products during oral administration for 28 days. AG: aloe fermentation product from Ganoderma lucidum, AH: aloe fermentation product from Hericium erinaceum, AP: aloe fermentation product from Phellinus linteus.

of female rats were not different between control and treatment groups (Table 3).

\section{Hematology}

The effects of aloe fermentation products on hematological parameters were determined in order to evaluate whether the tested products influence the normal values of the blood composition and their contents. In comparison with the vehicle control, hematocrit, RBC counts and RBC indices (hemoglobin,
$\mathrm{MCV}, \mathrm{MCH}$ and $\mathrm{MCHC}$ ), platelets, WBC counts and their proportions (\%) were not changed by treatment with 3 aloe fermentation products in female rats (Table 4) as well as in male animals (data not shown).

\section{Blood biochemistry}

Sera were analyzed for the adverse effects (tissue injury and dysfunction) of aloe fermentation products on tissues and organs. Table 5 and 6 depicts blood biochemical 
Table 2. Organ weights of male rats treated with aloe fermentation products for 4 weeks

\begin{tabular}{|c|c|c|c|c|c|c|c|c|c|c|}
\hline \multirow{2}{*}{ Organ } & \multirow{2}{*}{ Vehicle } & \multicolumn{3}{|c|}{$A G$} & \multicolumn{3}{|c|}{$\mathrm{AH}$} & \multicolumn{3}{|c|}{$\mathrm{AP}$} \\
\hline & & $(0.5 \mathrm{~g} / \mathrm{kg})$ & $(1 \mathrm{~g} / \mathrm{kg})$ & $(2 \mathrm{~g} / \mathrm{kg})$ & $(0.5 \mathrm{~g} / \mathrm{kg})$ & $(1 \mathrm{~g} / \mathrm{kg})$ & $(2 \mathrm{~g} / \mathrm{kg})$ & $(0.5 \mathrm{~g} / \mathrm{kg})$ & $(1 \mathrm{~g} / \mathrm{kg})$ & $(2 \mathrm{~g} / \mathrm{kg})$ \\
\hline Liver & $10.83 \pm 0.49$ & $11.21 \pm 0.92$ & $11.31 \pm 1.36$ & $11.06 \pm 1.20$ & $11.64 \pm 1.76$ & $10.90 \pm 0.76$ & $11.27 \pm 1.95$ & $11.24 \pm 0.57$ & $11.30 \pm 1.54$ & $11.83 \pm 1.57$ \\
\hline Kidney (left) & $1.27 \pm 0.09$ & $1.32 \pm 0.06$ & $1.26 \pm 0.09$ & $1.34 \pm 0.09$ & $1.21 \pm 0.13$ & $1.33 \pm 0.11$ & $1.25 \pm 0.12$ & $1.27 \pm 0.05$ & $1.35 \pm 0.16$ & $1.35 \pm 0.18$ \\
\hline Kidney (right) & $1.28 \pm 0.08$ & $1.32 \pm 0.09$ & $1.27 \pm 0.05$ & $1.34 \pm 0.13$ & $1.26 \pm 0.15$ & $1.28 \pm 0.11$ & $1.25 \pm 0.14$ & $1.29 \pm 0.06$ & $1.37 \pm 0.14$ & $1.33 \pm 0.10$ \\
\hline Lung & $1.34 \pm 0.08$ & $1.46 \pm 0.02$ & $1.45 \pm 0.13$ & $1.39 \pm 0.18$ & $1.45 \pm 0.10$ & $1.49 \pm 0.13$ & $1.35 \pm 0.14$ & $1.44 \pm 0.14$ & $1.48 \pm 0.07$ & $1.41 \pm 0.18$ \\
\hline Heart & $1.21 \pm 0.12$ & $1.17 \pm 0.13$ & $1.17 \pm 0.15$ & $1.19 \pm 0.03$ & $1.17 \pm 0.13$ & $1.20 \pm 0.07$ & $1.17 \pm 0.12$ & $1.15 \pm 0.10$ & $1.25 \pm 0.13$ & $1.15 \pm 0.05$ \\
\hline Thymus & $0.62 \pm 0.10$ & $0.69 \pm 0.23$ & $0.56 \pm 0.10$ & $0.60 \pm 0.09$ & $0.69 \pm 0.15$ & $0.65 \pm 0.11$ & $0.66 \pm 0.14$ & $0.68 \pm 0.13$ & $0.64 \pm 0.09$ & $0.65 \pm 0.14$ \\
\hline Spleen & $0.79 \pm 0.07$ & $0.90 \pm 0.11$ & $0.84 \pm 0.10$ & $0.80 \pm 0.10$ & $0.69 \pm 0.37$ & $0.87 \pm 0.11$ & $0.82 \pm 0.10$ & $0.98 \pm 0.44$ & $0.83 \pm 0.13$ & $0.79 \pm 0.06$ \\
\hline Adrenal (left) & $0.02 \pm 0.00$ & $0.02 \pm 0.00$ & $0.02 \pm 0.00$ & $0.02 \pm 0.00$ & $0.02 \pm 0.00$ & $0.02 \pm 0.01$ & $0.02 \pm 0.00$ & $0.02 \pm 0.00$ & $0.02 \pm 0.00$ & $0.02 \pm 0.00$ \\
\hline Adrenal (right) & $0.02 \pm 0.00$ & $0.02 \pm 0.00$ & $0.02 \pm 0.00$ & $0.02 \pm 0.00$ & $0.02 \pm 0.00$ & $0.02 \pm 0.00$ & $0.02 \pm 0.00$ & $0.02 \pm 0.01$ & $0.02 \pm 0.01$ & $0.02 \pm 0.00$ \\
\hline Testis (left) & $1.61 \pm 0.17$ & $1.64 \pm 0.17$ & $1.63 \pm 0.07$ & $1.67 \pm 0.10$ & $1.55 \pm 0.15$ & $1.73 \pm 0.09$ & $1.64 \pm 0.15$ & $1.69 \pm 0.14$ & $1.84 \pm 0.04$ & $1.68 \pm 0.16$ \\
\hline Testis (right) & $1.63 \pm 0.13$ & $1.61 \pm 0.17$ & $1.67 \pm 0.07$ & $1.65 \pm 0.11$ & $1.58 \pm 0.15$ & $1.72 \pm 0.06$ & $1.61 \pm 0.13$ & $1.64 \pm 0.15$ & $1.81 \pm 0.06$ & $1.69 \pm 0.16$ \\
\hline Epididymis (left) & $0.42 \pm 0.05$ & $0.40 \pm 0.03$ & $0.40 \pm 0.04$ & $0.40 \pm 0.02$ & $0.38 \pm 0.02$ & $0.42 \pm 0.02$ & $0.41 \pm 0.03$ & $0.41 \pm 0.05$ & $0.46 \pm 0.05$ & $0.40 \pm 0.04$ \\
\hline Epididymis (right) & $0.39 \pm 0.02$ & $0.40 \pm 0.04$ & $0.38 \pm 0.03$ & $0.38 \pm 0.02$ & $0.37 \pm 0.02$ & $0.41 \pm 0.04$ & $0.38 \pm 0.03$ & $0.40 \pm 0.06$ & $0.44 \pm 0.05$ & $0.41 \pm 0.04$ \\
\hline
\end{tabular}

AG: aloe fermentation product fermented by Ganoderma lucidum, AH: aloe fermentation product fermented by Hericium erinaceum, AP: aloe fermentation product fermented by Phellinus linteus.

Table 3. Organ weights of female rats treated with aloe fermentation products for 4 weeks

\begin{tabular}{|c|c|c|c|c|c|c|c|c|c|c|}
\hline \multirow{2}{*}{ Organ } & \multirow{2}{*}{ Vehicle } & \multicolumn{3}{|c|}{$A G$} & \multicolumn{3}{|c|}{$\mathrm{AH}$} & \multicolumn{3}{|c|}{ AP } \\
\hline & & $(0.5 \mathrm{~g} / \mathrm{kg})$ & $(1 \mathrm{~g} / \mathrm{kg})$ & $(2 \mathrm{~g} / \mathrm{kg})$ & $(0.5 \mathrm{~g} / \mathrm{kg})$ & $(1 \mathrm{~g} / \mathrm{kg})$ & $(2 \mathrm{~g} / \mathrm{kg})$ & $(0.5 \mathrm{~g} / \mathrm{kg})$ & $(1 \mathrm{~g} / \mathrm{kg})$ & $(2 \mathrm{~g} / \mathrm{kg})$ \\
\hline Liver & $6.60 \pm 0.76$ & $6.66 \pm 0.83$ & $7.09 \pm 0.87$ & $6.88 \pm 1.28$ & $6.39 \pm 0.82$ & $6.72 \pm 1.10$ & $6.37 \pm 0.44$ & $6.46 \pm 0.76$ & $6.81 \pm 0.71$ & $6.97 \pm 1.07$ \\
\hline Kidney (left) & $0.76 \pm 0.04$ & $0.80 \pm 0.03$ & $0.78 \pm 0.07$ & $0.84 \pm 0.07$ & $0.77 \pm 0.11$ & $0.76 \pm 0.05$ & $0.75 \pm 0.05$ & $0.76 \pm 0.05$ & $0.80 \pm 0.09$ & $0.81 \pm 0.08$ \\
\hline Kidney (right) & $0.80 \pm 0.09$ & $0.79 \pm 0.06$ & $0.76 \pm 0.06$ & $0.82 \pm 0.08$ & $0.78 \pm 0.10$ & $0.73 \pm 0.06$ & $0.75 \pm 0.02$ & $0.75 \pm 0.05$ & $0.78 \pm 0.06$ & $0.80 \pm 0.09$ \\
\hline Lung & $1.08 \pm 0.11$ & $1.03 \pm 0.10$ & $1.09 \pm 0.05$ & $1.15 \pm 0.12$ & $1.05 \pm 0.05$ & $1.13 \pm 0.07$ & $1.08 \pm 0.07$ & $1.09 \pm 0.13$ & $1.12 \pm 0.10$ & $1.17 \pm 0.07$ \\
\hline Heart & $0.83 \pm 0.12$ & $0.79 \pm 0.03$ & $0.80 \pm 0.06$ & $0.77 \pm 0.20$ & $0.78 \pm 0.09$ & $0.79 \pm 0.05$ & $0.80 \pm 0.07$ & $0.81 \pm 0.05$ & $0.77 \pm 0.08$ & $0.83 \pm 0.07$ \\
\hline Thymus & $0.50 \pm 0.08$ & $0.42 \pm 0.07$ & $0.37 \pm 0.06$ & $0.54 \pm 0.19$ & $0.40 \pm 0.09$ & $0.35 \pm 0.04$ & $0.46 \pm 0.08$ & $0.40 \pm 0.09$ & $0.45 \pm 0.08$ & $0.45 \pm 0.07$ \\
\hline Spleen & $0.55 \pm 0.10$ & $0.52 \pm 0.07$ & $0.54 \pm 0.08$ & $0.58 \pm 0.10$ & $0.53 \pm 0.01$ & $0.59 \pm 0.06$ & $0.57 \pm 0.03$ & $0.54 \pm 0.05$ & $0.51 \pm 0.05$ & $0.60 \pm 0.06$ \\
\hline Adrenal (left) & $0.03 \pm 0.00$ & $0.03 \pm 0.00$ & $0.03 \pm 0.01$ & $0.04 \pm 0.01$ & $0.02 \pm 0.01$ & $0.03 \pm 0.01$ & $0.03 \pm 0.00$ & $0.03 \pm 0.00$ & $0.03 \pm 0.01$ & $0.03 \pm 0.00$ \\
\hline Adrenal (right) & $0.03 \pm 0.01$ & $0.03 \pm 0.01$ & $0.03 \pm 0.00$ & $0.03 \pm 0.01$ & $0.03 \pm 0.00$ & $0.03 \pm 0.01$ & $0.03 \pm 0.00$ & $0.03 \pm 0.00$ & $0.03 \pm 0.01$ & $0.03 \pm 0.01$ \\
\hline Uterus & $0.52 \pm 0.16$ & $0.64 \pm 0.30$ & $0.46 \pm 0.10$ & $0.42 \pm 0.03$ & $0.42 \pm 0.07$ & $0.39 \pm 0.10$ & $0.47 \pm 0.20$ & $0.49 \pm 0.09$ & $0.37 \pm 0.04$ & $0.43 \pm 0.04$ \\
\hline Ovary (left) & $0.06 \pm 0.01$ & $0.05 \pm 0.02$ & $0.05 \pm 0.01$ & $0.06 \pm 0.01$ & $0.04 \pm 0.02$ & $0.05 \pm 0.02$ & $0.05 \pm 0.02$ & $0.05 \pm 0.02$ & $0.05 \pm 0.02$ & $0.06 \pm 0.01$ \\
\hline Ovary (right) & $0.05 \pm 0.01$ & $0.04 \pm 0.00$ & $0.05 \pm 0.01$ & $0.05 \pm 0.02$ & $0.04 \pm 0.01$ & $0.05 \pm 0.02$ & $0.04 \pm 0.01$ & $0.05 \pm 0.01$ & $0.04 \pm 0.02$ & $0.05 \pm 0.00$ \\
\hline
\end{tabular}

AG: aloe fermentation product fermented by Ganoderma lucidum, AH: aloe fermentation product fermented by Hericium erinaceum, AP: aloe fermentation product fermented by Phellinus linteus. 
Table 4. Hematological analysis of female rats treated with aloe fermentation products for 4 weeks

\begin{tabular}{|c|c|c|c|c|c|c|c|c|c|c|}
\hline \multirow{2}{*}{ Parameters } & \multirow{2}{*}{ Vehicle } & \multicolumn{3}{|c|}{$A G$} & \multicolumn{3}{|c|}{$\mathrm{AH}$} & \multicolumn{3}{|c|}{ AP } \\
\hline & & $0.5 \mathrm{~g} / \mathrm{kg}$ & $1 \mathrm{~g} / \mathrm{kg}$ & $2 \mathrm{~g} / \mathrm{kg}$ & $0.5 \mathrm{~g} / \mathrm{kg}$ & $1 \mathrm{~g} / \mathrm{kg}$ & $2 \mathrm{~g} / \mathrm{kg}$ & $0.5 \mathrm{~g} / \mathrm{kg}$ & $1 \mathrm{~g} / \mathrm{kg}$ & $2 \mathrm{~g} / \mathrm{kg}$ \\
\hline Hematocrit (\%) & $47.54 \pm 2.47$ & $45.93 \pm 2.23$ & $46.48 \pm 2.15$ & $47.47 \pm 0.74$ & $51.14 \pm 3.75$ & $49.48 \pm 3.32$ & $48.42 \pm 3.20$ & $50.58 \pm 2.45$ & $48.36 \pm 2.00$ & $50.28 \pm 3.78$ \\
\hline $\mathrm{RBC}\left(1 \times 10^{6}\right.$ cells $\left./ \mu \mathrm{L}\right)$ & $7.59 \pm 0.30$ & $7.40 \pm 0.19$ & $7.46 \pm 0.38$ & $7.68 \pm 0.25$ & $8.26 \pm 0.75$ & $7.93 \pm 0.39$ & $7.88 \pm 0.44$ & $8.28 \pm 0.46$ & $7.93 \pm 0.32$ & $8.02 \pm 0.49$ \\
\hline Hemoglobin (g/dL) & $17.52 \pm 0.81$ & $16.80 \pm 0.72$ & $17.08 \pm 0.97$ & $17.23 \pm 0.21$ & $19.30 \pm 1.87$ & $18.34 \pm 0.80$ & $17.92 \pm 1.28$ & $18.62 \pm 1.08$ & $18.24 \pm 0.32$ & $18.60 \pm 1.30$ \\
\hline $\mathrm{MCV}(\mathrm{fL})$ & $62.58 \pm 1.02$ & $62.10 \pm 1.65$ & $62.28 \pm 1.21$ & $61.90 \pm 2.51$ & $62.06 \pm 2.00$ & $62.30 \pm 1.82$ & $61.92 \pm 1.65$ & $61.10 \pm 1.49$ & $61.02 \pm 0.63$ & $62.60 \pm 1.14$ \\
\hline $\mathrm{MCH}(\mathrm{g} / \mathrm{dL})$ & $23.06 \pm 0.28$ & $22.73 \pm 0.39$ & $22.88 \pm 0.62$ & $22.47 \pm 0.93$ & $23.36 \pm 0.52$ & $23.14 \pm 0.51$ & $22.74 \pm 0.68$ & $22.48 \pm 0.99$ & $23.00 \pm 0.91$ & $23.18 \pm 0.25$ \\
\hline $\mathrm{MCHC}(\mathrm{g} / \mathrm{dL})$ & $36.84 \pm 0.80$ & $36.60 \pm 0.83$ & $36.75 \pm 0.49$ & $36.27 \pm 0.25$ & $37.66 \pm 1.29$ & $37.12 \pm 0.94$ & $36.96 \pm 0.36$ & $36.78 \pm 0.71$ & $37.68 \pm 1.40$ & $37.03 \pm 0.35$ \\
\hline $\operatorname{PLT}\left(1 \times 10^{3}\right.$ cells $\left./ \mu \mathrm{L}\right)$ & $1,127.0 \pm 210.8$ & $1,402.3 \pm 160.7$ & $1,081.3 \pm 129.3$ & $1,100.7 \pm 242.7$ & $1,326.5 \pm 50.51$ & $1,380.00 \pm 100.61$ & $1,360.40 \pm 155.6$ & $1,260.8 \pm 126.51$ & $1,307.40 \pm 168.5$ & $1,330.5 \pm 181.3$ \\
\hline WBC $\left(1 \times 10^{3}\right.$ cells $\left./ \mu \mathrm{L}\right)$ & $4.06 \pm 1.04$ & $4.16 \pm 0.69$ & $4.02 \pm 0.19$ & $3.99 \pm 0.63$ & $3.98 \pm 1.20$ & $4.11 \pm 0.90$ & $3.91 \pm 1.06$ & $3.69 \pm 1.66$ & $3.16 \pm 0.68$ & $3.28 \pm 1.12$ \\
\hline Neutrophils (\%) & $6.25 \pm 1.91$ & $6.30 \pm 0.85$ & $4.70 \pm 1.13$ & $5.85 \pm 0.49$ & $6.50 \pm 1.51$ & $5.22 \pm 1.56$ & $5.92 \pm 1.82$ & $5.63 \pm 1.20$ & $5.93 \pm 1.31$ & $4.53 \pm 1.43$ \\
\hline Eosinophils (\%) & $0.78 \pm 0.45$ & $1.00 \pm 0.36$ & $1.33 \pm 0.49$ & $1.05 \pm 0.21$ & $1.10 \pm 0.36$ & $1.02 \pm 0.26$ & $0.76 \pm 0.31$ & $0.78 \pm 0.19$ & $0.87 \pm 0.15$ & $0.85 \pm 0.64$ \\
\hline Basophils (\%) & $0.18 \pm 0.05$ & $0.13 \pm 0.06$ & $0.23 \pm 0.06$ & $0.23 \pm 0.06$ & $0.13 \pm 0.05$ & $0.13 \pm 0.06$ & $0.14 \pm 0.09$ & $0.18 \pm 0.10$ & $0.18 \pm 0.08$ & $0.20 \pm 0.08$ \\
\hline Lymphocytes (\%) & $89.20 \pm 5.03$ & $88.05 \pm 3.34$ & $87.75 \pm 5.98$ & $87.60 \pm 4.97$ & $88.26 \pm 4.11$ & $91.46 \pm 4.44$ & $91.26 \pm 1.62$ & $90.76 \pm 2.61$ & $90.18 \pm 2.11$ & $89.53 \pm 2.99$ \\
\hline Monocytes (\%) & $1.12 \pm 0.31$ & $1.58 \pm 0.55$ & $1.48 \pm 0.21$ & $1.27 \pm 0.21$ & $1.08 \pm 0.19$ & $1.23 \pm 0.47$ & $1.55 \pm 0.41$ & $1.53 \pm 0.46$ & $1.56 \pm 0.27$ & $1.15 \pm 0.30$ \\
\hline
\end{tabular}

AG: aloe fermentation product fermented by Ganoderma lucidum, AH: aloe fermentation product fermented by Hericium erinaceum, AP: aloe fermentation product fermented by Phellinus linteus. RBC: red blood cells, MCV: mean corpuscular volume, MCH: mean corpuscular hemoglobin, MCHC: mean corpuscular hemoglobin concentration, PLT: platelets, WBC: while blood cells.

Table 5. Blood biochemistry of male rats treated with aloe fermentation products for 4 weeks

\begin{tabular}{|c|c|c|c|c|c|c|c|c|c|c|}
\hline \multirow{2}{*}{ Parameters } & \multirow{2}{*}{ Vehicle } & \multicolumn{3}{|c|}{$A G$} & \multicolumn{3}{|c|}{$\mathrm{AH}$} & \multicolumn{3}{|c|}{ AP } \\
\hline & & $0.5 \mathrm{~g} / \mathrm{kg}$ & $1 \mathrm{~g} / \mathrm{kg}$ & $2 \mathrm{~g} / \mathrm{kg}$ & $0.5 \mathrm{~g} / \mathrm{kg}$ & $1 \mathrm{~g} / \mathrm{kg}$ & $2 \mathrm{~g} / \mathrm{kg}$ & $0.5 \mathrm{~g} / \mathrm{kg}$ & $1 \mathrm{~g} / \mathrm{kg}$ & $2 \mathrm{~g} / \mathrm{kg}$ \\
\hline ALT (U/L) & $46.25 \pm 8.19$ & $50.32 \pm 1.37$ & $41.34 \pm 7.08$ & $42.03 \pm 6.84$ & $40.20 \pm 2.70$ & $41.18 \pm 5.83$ & $44.45 \pm 6.52$ & $42.98 \pm 9.60$ & $40.13 \pm 3.81$ & $40.90 \pm 1.89$ \\
\hline AST (U/L) & $196.72 \pm 14.81$ & $167.50 \pm 17.32$ & $168.00 \pm 22.81$ & $164.80 \pm 10.73$ & $162.90 \pm 11.33$ & $197.87 \pm 8.40$ & $177.92 \pm 5.36$ & $217.80 \pm 11.90$ & $196.40 \pm 19.16$ & $203.60 \pm 30.87$ \\
\hline ALP (U/L) & $380.68 \pm 50.84$ & $405.38 \pm 58.07$ & $362.58 \pm 27.06$ & $374.94 \pm 15.45$ & $353.55 \pm 38.00$ & $366.84 \pm 85.70$ & $403.34 \pm 53.09$ & $370.72 \pm 25.75$ & $378.13 \pm 73.19$ & $372.83 \pm 58.17$ \\
\hline TB (mg/dL) & $0.05 \pm 0.01$ & $0.03 \pm 0.02$ & $0.03 \pm 0.01$ & $0.02 \pm 0.01$ & $0.02 \pm 0.02$ & $0.03 \pm 0.01$ & $0.03 \pm 0.01$ & $0.03 \pm 0.01$ & $0.03 \pm 0.01$ & $0.03 \pm 0.01$ \\
\hline $\mathrm{TP}(\mathrm{g} / \mathrm{dL})$ & $5.06 \pm 0.53$ & $5.38 \pm 0.17$ & $5.00 \pm 0.25$ & $5.62 \pm 0.42$ & $5.26 \pm 0.23$ & $5.48 \pm 0.13$ & $5.78 \pm 0.16$ & $5.76 \pm 0.13$ & $5.62 \pm 0.39$ & $5.60 \pm 0.24$ \\
\hline Albumin $(\mathrm{g} / \mathrm{dL})$ & $3.04 \pm 0.25$ & $3.16 \pm 0.23$ & $3.22 \pm 0.21$ & $3.06 \pm 0.15$ & $2.70 \pm 0.33$ & $2.74 \pm 0.37$ & $3.08 \pm 0.20$ & $3.14 \pm 0.11$ & $2.92 \pm 0.10$ & $3.34 \pm 0.16$ \\
\hline $\mathrm{TC}(\mathrm{mg} / \mathrm{dL})$ & $74.16 \pm 7.43$ & $73.70 \pm 9.39$ & $77.10 \pm 10.03$ & $83.28 \pm 5.29$ & $77.96 \pm 18.92$ & $82.54 \pm 10.55$ & $85.64 \pm 15.53$ & $83.16 \pm 9.70$ & $83.12 \pm 11.28$ & $85.50 \pm 10.48$ \\
\hline TG (mg/dL) & $74.48 \pm 11.69$ & $82.20 \pm 10.31$ & $82.44 \pm 12.86$ & $82.42 \pm 16.50$ & $67.45 \pm 19.63$ & $73.78 \pm 8.50$ & $63.23 \pm 8.40$ & $63.08 \pm 17.53$ & $64.72 \pm 18.19$ & $64.95 \pm 8.23$ \\
\hline Glucose (mg/dL) & $96.76 \pm 14.76$ & $113.32 \pm 12.51$ & $113.06 \pm 8.62$ & $103.25 \pm 22.23$ & $112.05 \pm 6.81$ & $122.18 \pm 18.16$ & $104.72 \pm 18.59$ & $87.20 \pm 14.39$ & $108.26 \pm 19.16$ & $122.22 \pm 6.71$ \\
\hline BUN (mg/dL) & $16.36 \pm 2.85$ & $17.23 \pm 1.92$ & $15.18 \pm 2.57$ & $15.42 \pm 2.20$ & $15.37 \pm 0.75$ & $17.24 \pm 1.09$ & $16.54 \pm 0.48$ & $16.92 \pm 2.09$ & $15.47 \pm 2.04$ & $15.90 \pm 1.28$ \\
\hline Creatinine (mg/dL) & $0.38 \pm 0.08$ & $0.42 \pm 0.04$ & $0.38 \pm 0.04$ & $0.46 \pm 0.05$ & $0.38 \pm 0.04$ & $0.46 \pm 0.05$ & $0.46 \pm 0.05$ & $0.46 \pm 0.08$ & $0.44 \pm 0.05$ & $0.48 \pm 0.04$ \\
\hline
\end{tabular}

AG: aloe fermentation product fermented by Ganoderma lucidum, AH: aloe fermentation product fermented by Hericium erinaceum, AP: aloe fermentation product fermented by Phellinus

linteus. ALT: alanine transaminase, AST: aspartate transaminase, ALP: alkaline phosphatase, TB: total bilirubin, TP: total proteins, TC: total cholesterol, TG: triglycerides, BUN: blood urea

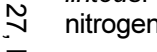


Table 6. Blood biochemistry of female rats treated with aloe fermentation products for 4 weeks

\begin{tabular}{|c|c|c|c|c|c|c|c|c|c|c|}
\hline \multirow{2}{*}{ Parameters } & \multirow{2}{*}{ Control } & \multicolumn{3}{|c|}{ AG } & \multicolumn{3}{|c|}{$\mathrm{AH}$} & \multicolumn{3}{|c|}{$\mathrm{AP}$} \\
\hline & & $0.5 \mathrm{~g} / \mathrm{kg}$ & $1 \mathrm{~g} / \mathrm{kg}$ & $2 \mathrm{~g} / \mathrm{kg}$ & $0.5 \mathrm{~g} / \mathrm{kg}$ & $1 \mathrm{~g} / \mathrm{kg}$ & $2 \mathrm{~g} / \mathrm{kg}$ & $0.5 \mathrm{~g} / \mathrm{kg}$ & $1 \mathrm{~g} / \mathrm{kg}$ & $2 \mathrm{~g} / \mathrm{kg}$ \\
\hline ALT (U/L) & $34.66 \pm 3.42$ & $36.82 \pm 6.28$ & $37.84 \pm 4.85$ & $38.74 \pm 5.85$ & $36.86 \pm 7.82$ & $34.38 \pm 5.76$ & $32.74 \pm 5.96$ & $34.88 \pm 8.47$ & $38.46 \pm 3.35$ & $37.06 \pm 3.61$ \\
\hline AST (U/L) & $147.40 \pm 23.95$ & $161.75 \pm 44.64$ & $175.13 \pm 11.78$ & $166.27 \pm 15.39$ & $185.63 \pm 19.88$ & $167.00 \pm 19.85$ & $141.15 \pm 21.84$ & $152.60 \pm 7.37$ & $152.25 \pm 15.61$ & $161.37 \pm 46.10$ \\
\hline ALP (U/L) & $220.33 \pm 39.77$ & $231.43 \pm 26.61$ & $241.80 \pm 27.43$ & $246.80 \pm 15.80$ & $202.40 \pm 29.29$ & $203.20 \pm 23.74$ & $189.35 \pm 12.58$ & $230.88 \pm 19.23$ & $196.90 \pm 16.37$ & $193.80 \pm 21.91$ \\
\hline $\mathrm{TB}(\mathrm{mg} / \mathrm{dL})$ & $0.17 \pm 0.02$ & $0.14 \pm 0.04$ & $0.16 \pm 0.02$ & $0.14 \pm 0.04$ & $0.13 \pm 0.03$ & $0.13 \pm 0.02$ & $0.13 \pm 0.01$ & $0.15 \pm 0.01$ & $0.15 \pm 0.01$ & $0.13 \pm 0.02$ \\
\hline $\mathrm{TP}(\mathrm{g} / \mathrm{dL})$ & $5.42 \pm 0.49$ & $5.24 \pm 0.40$ & $5.76 \pm 0.18$ & $5.60 \pm 0.14$ & $5.72 \pm 0.48$ & $5.64 \pm 0.30$ & $5.64 \pm 0.35$ & $5.82 \pm 0.17$ & $5.48 \pm 0.13$ & $5.74 \pm 0.55$ \\
\hline Albumin (g/dL) & $3.92 \pm 0.31$ & $3.88 \pm 0.35$ & $4.14 \pm 0.15$ & $4.14 \pm 0.20$ & $4.22 \pm 0.36$ & $4.12 \pm 0.13$ & $4.12 \pm 0.25$ & $4.28 \pm 0.13$ & $3.98 \pm 0.22$ & $4.22 \pm 0.48$ \\
\hline $\mathrm{TC}(\mathrm{mg} / \mathrm{dL})$ & $92.12 \pm 13.40$ & $82.46 \pm 20.15$ & $99.34 \pm 17.85$ & $88.22 \pm 10.79$ & $96.78 \pm 24.37$ & $99.34 \pm 17.85$ & $99.34 \pm 17.82$ & $94.86 \pm 16.56$ & $103.46 \pm 11.83$ & $93.02 \pm 15.76$ \\
\hline $\mathrm{TG}(\mathrm{mg} / \mathrm{dL})$ & $76.28 \pm 18.02$ & $71.00 \pm 16.44$ & $75.64 \pm 17.34$ & $66.83 \pm 11.68$ & $66.45 \pm 28.86$ & $52.30 \pm 6.81$ & $53.75 \pm 4.84$ & $51.34 \pm 12.31$ & $57.35 \pm 16.22$ & $55.83 \pm 6.86$ \\
\hline Glucose (mg/dL) & $107.72 \pm 7.75$ & $114.58 \pm 18.62$ & $111.43 \pm 10.36$ & $116.87 \pm 7.29$ & $102.12 \pm 14.14$ & $100.48 \pm 17.64$ & $104.28 \pm 11.68$ & $103.56 \pm 17.06$ & $102.12 \pm 9.39$ & $111.55 \pm 7.25$ \\
\hline $\mathrm{BUN}(\mathrm{mg} / \mathrm{dL})$ & $14.12 \pm 0.75$ & $13.78 \pm 2.35$ & $17.54 \pm 0.79$ & $14.60 \pm 1.20$ & $16.96 \pm 1.24$ & $16.60 \pm 2.20$ & $15.72 \pm 0.66$ & $15.94 \pm 1.35$ & $15.88 \pm 2.13$ & $16.98 \pm 1.90$ \\
\hline Creatinine (mg/dL) & $0.42 \pm 0.04$ & $0.46 \pm 0.05$ & $0.44 \pm 0.05$ & $0.54 \pm 0.05$ & $0.48 \pm 0.04$ & $0.05 \pm 0.07$ & $0.46 \pm 0.05$ & $0.46 \pm 0.05$ & $0.46 \pm 0.05$ & $0.50 \pm 0.07$ \\
\hline
\end{tabular}

AG: aloe fermentation product fermented by Ganoderma lucidum, AH: aloe fermentation product fermented by Hericium erinaceum AP: aloe fermentation product fermented by Phellinus linteus. ALT: alanine transaminase, AST: aspartate transaminase, ALP: alkaline phosphatase, TB: total bilirubin, TP: total proteins, TC: total cholesterol, TG: triglycerides, BUN: blood urea nitrogen. 
parameters of rats fed the aloe fermentation products. The test materials at 3 different doses did not affect the normal values of all 11 biochemical parameters in both males (Table 5) and females (Table 6). The parameters cover hepatocytic injury (ALT and AST), cholestasis (ALP and TB), hepatocytic protein synthesis (TP and albumin), lipid metabolism (TC and TG), energy synthesis and storage (glucose), and renal dysfunction (BUN and creatinine).

\section{Histopathological findings}

Histopathological examination of the vital organs of the rats fed aloe fermention products for 4 weeks were determined using hematoxylin-eosin staining techniques. All 3 aloe fermention products did not induce any histological lesions in organs including liver, lung, spleen, kidneys, heart, testes, ovaries, adrenal glands, thymus and brain (data not shown). The intact histological findings under microscopic examination well correlates with the normal organ weights, hematology and blood biochemical parameters.

We obtained 3 aloe fermentation products by fermenting aloe with 3 mushroom mycelia: aloin $\mathrm{A}$ and $\mathrm{B}$ contents in AG from Ganoderma lucidum, $\mathrm{AH}$ from Hericium erinaceus (AH) and AP from Phellinus linteus greatly increased, while the $\beta$-glucan content significantly decreased. In the present studies, we investigated any possible toxicities of the 3 aloe fermentation products in rats following oral administration once (at doses of 1,2 and $5 \mathrm{~g} / \mathrm{kg}$ ) or for 28 days (at doses of $0.5,1$ and $2 \mathrm{~g} / \mathrm{kg}$ ).

There was no significant difference in body weight gain between vehicle control and $\mathrm{AG}$-, $\mathrm{AH}$ - or AP-treated rats. Also, significant changes in daily feed intake and water consumption were not observed. In hematological analysis, non of the parameters observed were affected by aloe fermentation products with mushroom mycelia, suggestive of no adverse effects on hematopoiesis of blood cells and their integrity. In blood biochemistry, none of the markers examined were affected by AG, AH or AP feeding. Similarly, there were no significant effects on damage and functional markers of the liver and kidneys. Supportive of the above parameters, histopathological findings confirmed that the aloe fermentation products did not cause any lesions in major internal organs. In conclusion, since no adverse effects of AG, AH or AP were observed in single- or repeated-dose toxicity tests, even at upper-limit doses, it is suggested that aloe fermentation products with mushroom mycelia possess long-term safety and could be candidates for the improvement of intestinal function and immunity.

\section{Acknowledgments}

This work was supported by a grant (S1066014) from the Small and Medium Business Administration of Korea in 2009.

\section{References}

1. Cho YJ, An BJ, Kim MU, Shim CS. Anti-inflammatory effect of Aloe vera and aloe arborescens in phosphatidic acidstimulated raw cells. Korean J Soc Appl Biol Chem 2006; 49(1): 65-69.

2. Kang MH, Cho SY, Kim HS, Kim DH, Jeong CS. Antigastritic and antiulcerative effect of Pulmuone Healthy Aloe Gel. Korean J Pharm Soc 2005; 49(3): 237-243.

3. Hong HS, Lee $\mathrm{KH}$, Kim JH, Kang $\mathrm{HG}$, Cho $\mathrm{CH}$, Kim $\mathrm{CH}$. The Comparative of inhibitory effect of various solvent extracts from Aloe arborescens and Aloe vera on tumor cell lines using clonoginic assay. Korean J Pharmacogn 1999; 30(3): 275-279.

4. Lee YW, Roh WS, Kim JG, Kim PG. Effects of Aloe vera on the cholesterol and vitamin $\mathrm{D}_{2}$-induced atherosclerosis in rats. J Fd Hyg Safety 1996; 11(4): 243-259.

5. Woo N, Ahn MS, Lee SY. Antioxidative Effect of Aloe (Aloe arborescences) Extracts on Linoleic Acid and Soybean Oil. Korean J Soc Food Sci 1995; 11(5): 536-541.

6. Jeong HY, Kim JH, Hwang SJ, Rhee DK. Anticancer effects of aloe on sarcoma 180 in ICR mouse and on human cancer cell lines. Korean J Pharm Soc 1994; 38(3): 311-321.

7. Lee GD, Chang HG, Kim HK. Antioxidative and nitritescavenging activities of edible mushrooms. Korean J Food Sci Technol 1997; 29(3): 432-436.

8. Lee BW, Lee MS, Park KM, Kim CH, Ahn PU, Choi CU. Anticancer activities of the extract from the mycelia of Coriolus versicolor. Kor J Appl Microbiol Biotechnol 1992; 20(3): 311-315.

9. Lee SY, Kang TS, Moon SO, Lew ID, Lee MY. Fractionation and antitumor activity of the water soluble exo-polysaccharide by submerged cultivation of Ganoderma lucidum mycelium. Kor J Appl Microbiol Biotechnol 1996; 24(4): 459-464.

10. Kim SW, Kim ES, Kim YS. Studies on the polysaccharide extracted from Ganoderma lucidum. J Korean Soc Food Nutr 1995; 24(1): 147-153.

11. Kim Yl, Kim BK, Jeong $\mathrm{H}$, Lee KH. Production of Antihypertensive constituents from Ganoderma lucidum IY005 by fermentation using industrial wastes. Korean J Mycol 1991; 19(1): 79-84.

12. Hwang KH, Kim HK, Han YN. Screening of inhibitory activity of edible mushrooms on dopamine $\beta$-hydroxylase. Korean J Food Sci Technol 1997; 29(2): 194-197.

13. Kim SH, Lee JN, Kim SH, Oh SJ, An SW, Lee JH, Park YS, Chung EK, Lee HY. Studies on screening and comparison of biological activities from the fruiting body and mycelium of Elfvingia applanata. Kor. J Appl Microbiol Biotechnol 1998; 26(4), 331-337.

14. Oh SI, Lee MS. Antioxidative and antimutagenic effects of Ganoderma lucidum Krast extracts. Korean J Food Nutr 2005; 18(1): 54-62.

15. Seo KW, Cho IS, Oh MH, Lee KM, Kim HJ. Subacute toxicity of G009, a polysaccharide isolated from Ganoderma lucidum IY009. J Fd Hyg Safety 1996; 11(4): 261-271.

16. Bae HS, Kang SK, Shin IS, Woo SK, Kim YJ, Kim MA, Ra JC. The effects of extracts mixture drink from Inonotus obliquus, Phellinus linteus and Ganoderma lucidum on hematopoietic stem cells and lymphocyte subset of blood in human. J Fd 
Hyg Safety 2009; 24(1): 78-85.

17. Joung EM, Hwang IG, Lee HY, Jeong JH, Yu KW, Jeong HS Changes of saponin and $\beta$-glucan content on the cultured ginseng with mushroom mycelia. J Kor Soc Food Sci Nutr 2009; 38(8): 1084-1089.

18. Jeong JH, Wee JJ, Shin JY, Cho JH, Jung DH. Antioxidative effect of crude saponin fraction prepared from culture product of Basidiomycota cultured with fresh ginseng as substrate. Korean J Food Sci Technol 2005; 37(1): 67-72.

19. Choi MA, Park NY, Woo SM, Jeong YJ, Shin SR. Characteristics of Hericium erinaceus and its extracts. Korean J Food Preserv 2003; 10(4): 560-564.

20. Jung $\mathrm{JH}$, Lee KE, Lee SY. Optimization of submerged cultivation of Hericium erinaceum. Korean J Biotechnol Bioeng 2006; 21(2): 96-102.

21. Park JS, Chang KW, Nam YG. Analysis of barbaloin in the Aloe vera depending on the various extracting conditions. Korean J Soc Agr Chem Biotechnol 1994; 37(5) 409-413.
22. Chang KW, Park JS, Jang GC. Fatty and organic acids, and barbaloin in various parts of Aloe species dried at different drying temperatures. J Korean Agric Chem Soc 1993; 36(4) 244-248.

23. Um S, Jin GE, Park KW, Yu YB, Park KM. Physiological activity and nutritional composition of Pleurotus species. Korean J Food Sci Technol 2010; 42(1): 90-96.

24. Sung IJ, Park MY, Kim JD. Mouse single oral dose toxicity test and bone marrow micronucleus test of Mahwangbujaseshintang extracts. Korean J Oriental Physiol Path 2010; 24(1); 124-133.

25. Jung WC, Lee JH, Choi WJ, Kim S, Lee HJ. Four-week repeated-dose toxicity study of sodium chlorate in mice. Lab Anim Res 2009; 25(4); 355-362.

26. Kim TM, Ryu JM, Seo IK, Yeon S, Lim WT, Lee JY, Hwang SY, Kim YB. Four-week repeated-dose toxicity of silk amino acids in rats. Lab Anim Res 2008; 24(4); 565-573. 